\title{
PSYCHOLOGICAL CAPITAL DAN STRES KERJA PADA KARYAWAN DI PT. MN
}

\section{Psychological Capital and Work Stress of Employees in PT. MN}

\author{
Meiliana \\ Program Studi Psikologi Universitas Bunda Mulia \\ Diterima 1 Maret 2020/ Disetujui 5 April 2020
}

\begin{abstract}
Since MEA has been attained, demands and competition for labor force at this time the higher resulting vulnerable workers experiencing job stress. High work stress experienced by employees PT.MN. The phenomenon of job stress experienced by employees MN make researchers interested in the correlation between psychological stress of working capital to be owned by employees MN. This study uses a quantitative approach to the type of correlational research. The study involved $153 \mathrm{MN}$ employees who have worked for more than six months. Data obtained through the research instruments and analyzed using SPSS 17. To determine the correlation between psychological capital with work stress on employees $M N$, researchers using Pearson correlation. The results showed a picture of psychological low capital and high work stress. Pearson correlation test results showed that there was a significant negative correlation strong between psychological capital with work stress on employees MN. In addition, the researchers also conducted a correlation between each dimension of psychological capital (self-efficacy, hope, resiliency and optimism) with work stress. The results also show that every dimension of psychological capital has a significant negative relationship with job stress. Given these correlations, for the MN should improve psychological capital that employees so work stress can be reduced. This will provide a positive impact on the progress of employees and companies
\end{abstract}

Keywords: psychological capital, work stress, employee

\begin{abstract}
ABSTRAK
Tuntutan dan persaingan tenaga tenaga kerja saat ini semakin tinggi sehingga mengakibatkan pekerja rentan mengalami stres kerja. Stres kerja yang tinggi dialami oleh karyawan PT.MN. Melihat adanya fenomena stres kerja yang dialami karyawan MN membuat peneliti tertarik untuk melihat kaitan antara psychological capital dengan stres kerja yang dimiliki oleh karyawan MN. Penelitian ini menggunakan pendekatan kuantitatif dengan jenis penelitian korelasional. Penelitian ini melibatkan 153 karyawan MN yang telah bekerja selama lebih dari enam bulan. Data diperoleh melalui instrumen penelitian dan dianalisis menggunakan program SPSS 17. Untuk mengetahui hubungan antara psychological capital dengan stres kerja pada karyawan MN, peneliti menggunakan korelasi Pearson. Hasil penelitian menunjukkan gambaran psychological capital yang rendah dan stres kerja yang tinggi. Hasil uji korelasi Pearson menunjukkan bahwa terdapat hubungan negatif signifikan yang kuat antara psychological capital dengan stres kerja pada karyawan MN. Dengan adanya korelasi tersebut, bagi pihak MN sebaiknya meningkatkan psychological capital yang dimiliki karyawan agar stres kerja dapat berkurang. Hal ini akan memberikan dampak positif bagi kemajuan karyawan maupun perusahaan.
\end{abstract}

Kata Kunci: psychological capital, stress kerja, karyawan

\section{PENDAHULUAN}

Standar kualitas yang diberikan perusahaan kepada tenaga kerja saat ini semakin tinggi untuk berkompetisi mendapatkan pekerjaan di Indonesia, apalagi semenjak diberlakukannya MEA

\footnotetext{
*Korespondensi Penulis:

meilianaami@gmail.com
}

(Masyarakat Ekonomi Asean). Tenaga kerja yang dipilih adalah tenaga kerja yang memiliki mental, komitmen, kompetensi, keterampilan, kedisiplinan dan budaya kerja yang baik demi mencapai tujuan dan meningkatkan kinerja perusahaan secara optimal (Tando, 2015). Menurut Karasek (dalam Revalicha dan Samian, 2013) stres kerja adalah interaksi yang muncul antara 
Versi Online: http://journal.ubm.ac.id/index.php/psibernetika DOI: 10.30813/psibernetika.v13i1.2313 Hasil Penelitian

tuntutan psikologis pada suatu pekerjaan dengan kontrol terhadap pekerjaan dan dukungan sosial di tempat kerja, dimana tuntutan psikologis pada pekerjaan tinggi serta kontrol dan dukungan sosial di tempat kerja rendah. Pemicu stres lebih banyak disebabkan karena lingkungan profesional misalnya dengan pekerjaan, manajemen dan keuangan pribadi merupakan faktor utama penyebabnya (Revalicha \& Samian, 2013). Stres memiliki dampak negatif bagi kesehatan jasmani, perilaku dan lingkungan. Stres kerja dapat membuat karyawan membolos, tidak semangat dalam bekerja dan meningkatkan jumlah karyawan yang keluar (turn over). Hal-hal tersebut memberikan dampak negatif bagi perusahaan, yaitu timbulnya kekacauan dan hambatan baik dalam manajemen maupun operasional kerja, menurunkan tingkat produktivitas serta menurunkan pemasukan dan keuntungan perusahaan (Sinaga \& Sunardi, 2013).

Fenomena diatas menunjukkan pentingnya masalah stres kerja untuk dapat diatasi agar perusahaan tidak mengalami kerugian sehingga hal ini membuat peneliti tertarik untuk melihat konsep psikologi yang membahas mengenai sumber daya manusia. Salah satu konsep psikologi industri dan organisasi yang membahas mengenai sumber daya manusia adalah positive organizational behavior. Positive organizational behavior berawal dari konsep psikologi positif yang dikembangkan dalam konteks tempat kerja. Konsep positive organizational behavior berorientasi pada kekuatan dan kapasitas psikologis sumber daya manusia yang dapat diukur, dikembangkan dan dikelola guna peningkatan kinerja di tempat kerja yang dikenal dengan istilah psychological capital atau modal psikologis (Luthans \& Youssef dalam Dewi, 2015). Dalam psychological capital, yang disingkat dengan psycap, kelebihan atau kekuatan individu tampak dari keadaan psikologis positif individu yang dikarekteristikkan dengan memiliki keyakinan untuk melakukan dan terlibat dalam usaha yang diperlukan agar berhasil dalam tugas yang menantang (self efficacy),
Jurnal Psibernetika

Vol.13 (No.1) : 9 -19. Th. 2020

p-ISSN: 1979-3707

e-ISSN: 2581-0871

memiliki atribut positif saat ini dan ke depan secara berturut-turut (optimism), tidak mudah menyerah terhadap tujuan dan ketika dibutuhkan mampu mengarahkan menuju tujuan untuk mencapai sukses (hope), dan ketika dihadapkan pada masalah dan kesulitan mampu bertahan dan melambung dan bahkan melebihi untuk meraih sukses (resiliency) (Luthans, Youssef \& Avolio, 2007).

Perkembangan industri di bidang media saat ini tergolong kompetitif dan menuntut kinerja pekerja yang tinggi. Tuntutan pekerjaan di bidang media menyebabkan pekerja rentan terhadap stres.

Salah satu perusahaan media yang berkembang di Indonesia yaitu, PT MNC (Media Nusantara Citra). Salah satu cabang perusahaan MNC yang menjadi responden dalam penelitian adalah karyawan di PT MN (PT Media Nusantara Citra Networks). Berdasarkan observasi yang dilakukan, peneliti mengamati bahwa karyawan $\mathrm{MN}$ sibuk bekerja setiap harinya. Hal ini ditunjukkan dengan karyawan yang terlihat fokus dan serius dalam mengerjakan tugasnya, jarang terlihat bermain ataupun bercanda, dan pada saat jam pulang kantor, bahkan masih cukup banyak karyawan yang masih mengerjakan tugasnya di kantor. Berdasarkan hasil observasi dan wawancara terhadap stres kerja dan psychological capital yang telah peneliti lakukan kepada 10 orang karyawan $\mathrm{MN}$, terlihat tingkat stres dan gambaran psychological capital yang beragam ditunjukkan oleh masingmasing karyawan. Sementara itu, hasil penelitian yang dilakukan oleh Avey, Luthans, dan Jensen (2009) mengenai sumber positif untuk mengatasi stres dan turn over karyawan, menyatakan bahwa karyawan sebaiknya mengembangkan psychological capital agar dapat mengatasi stres kerja yang dihadapi dengan lebih baik. Akan tetapi, penelitian mengenai psychological capital dengan stres kerja masih sangat jarang dilakukan di Indonesia dan pada karyawan MN, belum terlihat 
apakah psychological capital yang dimiliki oleh karyawan memiliki hubungan dengan stres kerja. Selain itu psychological capital merupakan gabungan teori dari self efficacy, hope, resiliency dan optimism sehingga penelitian ini diharapkan dapat memberikan informasi yang lebih banyak. Hal inilah yang membuat peneliti tertarik untuk meneliti apakah terdapat hubungan antara psychological capital dengan stres kerja pada karyawan PT.MN.

\section{Tujuan Penelitian}

Tujuan dari penelitian ini adalah untuk mengetahui gambaran psychological capital, gambaran stres kerja, hubungan antara psychological capital dengan stres kerja pada karyawan PT.MN.

\section{Tinjauan Teori}

\section{Psychological Capital}

Menurut Luthans \& Youssef (dalam Dewi, 2015) psychological capital merupakan konsep yang berasal dari konsep psikologi mengenai positive psychology. Positive psychology yang dikembangkan dalam konteks tempat kerja disebut dengan positive organizational behavior. Konsep positive organizational behavior berorientasi pada kekuatan dan kapasitas psikologis sumber daya manusia yang dapat diukur, dikembangkan dan dikelola guna peningkatan kinerja di tempat kerja disebut dengan positive psychological capital atau psychological capital. Psychological Capital memiliki empat dimensi yaitu:

- Self Efficacy merupakan keyakinan untuk melakukan dan terlibat dalam usaha yang diperlukan agar berhasil dalam tugas yang menantang (Luthans \& Youssef, 2007). Keyakinan diri seseorang membuatnya memilih tugas yang menantang dan melakukan usaha untuk berhasil mencapai tujuan yang diinginkan. Individu dengan self efficacy yang tinggi juga memiliki motivasi diri, target atau tujuan yang tinggi, dan mampu bertahan ketika dihadapkan pada rintangan dan mendukung proses kerja dan pencapaian kinerja.

- Hope menurut Snyder (dalam Luthans, Youssef \& Avolio, 2007) sebagai suatu motivasi positif yang didasarkan pada suatu perasaan keberhasilan dari: 1) agency (energi yang terarah pada tujuan), dan 2) pathways (rencana mencapai tujuan). Penelitian Snyder, mendukung ide bahwa hope adalah keadaan kognitif dimana seseorang mampu menetapkan tujuan-tujuan dan pengharapan yang menantang manun realistis dan kemudian mencoba mencapai tujuan-tujuan tersebut dengan kemampuan sendiri, energi, dan persepsi control internal. Hal inilah yang disebut oleh Snyder sebagai agency atau willpower. Pada komponen pathways atau waypower, seseorang mampu menciptakan jalur-jalur alternatif untuk mencapai tujuan yang mereka inginkan ketika jalur asalnya tertutup atau mendapat halangan.

- Optimism adalah suatu explanatory style yang memberikan atribusi peristiwa-peristiwa positif pada sebab-sebab yang personal, permanent, serta pervasive dan menginterpretasikan peristiwaperistiwa negatif pada faktor-faktor yang eksternal, sementara, serta situasional.

Sebaliknya, explanatory style yang pesimistis akan menginterpretasikan peristiwa positif dengan atribusi-atribusi yang eksternal, Sementara, serta situasional dan mengatribusi peristiwa negatif pada penyebab yang personal, permanent dan pervasive (Seligman, dalam Luthans, Youssef \& Avolio, 2007).

- Resiliency menurut Masten dan Reed (dalam Luthans, Youssef \& Avolio, 2007) tidak hanya kemampuan untuk kembali dari 
Versi Online: http://journal.ubm.ac.id/index.php/psibernetika DOI: 10.30813/psibernetika.v13i1.2313

Hasil Penelitian

situasi keterpurukan namun juga terlibat dalam kegiatan-kegiatan yang positif dan menantang, misalnya target penjualan, dan kemauan untuk berusaha melebihi normal atau melebihi poin keseimbangan.

\section{Stres Kerja}

Karasek (dalam Revalicha dan Samian, 2013) mengemukakan stres kerja sebagai interaksi yang muncul antara tuntutan psikologi pada suatu pekerjaan dengan kontrol terhadap pekerjaan tersebut dan dukungan sosial di tempat kerja, dimana tuntutan psikologis pada pekerjaan tinggi serta kontrol dan dukungan sosial di tempat kerja rendah.

Menurut Karasek (dalam Revalicha \& Samian, 2013), dimensi stres kerja terbagi menjadi tiga. Pertama, demands / tuntutan kerja : persepsi seseorang mengenai seberapa keras ia bekerja, di mana subdimensi yang digunakan adalah beban kerja (workload), tekanan dalam waktu, dan personal conflict. Kedua, control Pekerja memiliki kewenangan untuk menggunakan kemampuan intelektualnya dalam melakukan pekerjaan yang berhubungan dengan kerjanya, berbagai macam keterampilan dibutuhkan untuk menyelesaikan pekerjaan, berkaitan dengan mempelajari keterampilan baru, pengembangan kompetensi, dan penggunaan kreatifitas dalam menyelesaikan pekerjaan (skill discretion) serta pekerja memiliki kewenangan untuk membuat keputusan tentang bagaimana melakukan tugas tersebut (Decision authority). Ketiga, social support yaitu dukungan sosial yang diberikan meliputi kerja sama dan tingkat interaksi sosial antara rekan kerja maupun atasan.

Kurangnya dukungan juga dapat menimbulkan konsekuensi negatif untuk kesehatan. Permusuhan antar pribadi juga termasuk sebagai ukuran dukungan sosial. Dengan adanya dukungan sosial, dapat membuat pekerja mengurangi stres kerja yang dirasakan.
Jurnal Psibernetika

Vol.13 (No.1) : 9 -19. Th. 2020

p-ISSN: 1979-3707

e-ISSN: 2581-0871

\section{METODE PENELITIAN}

Penelitian ini menggunakan metode penelitian kuantitatif. Jenis penelitian kuantitatif yang digunakan peneliti adalah penelitian korelasional. Penelitian korelasional adalah dua atau lebih variabel diukur untuk memperoleh sekumpulan skor (biasanya dua skor) untuk setiap individual. Pengukuran diuji untuk mengidentifikasi pola hubungan yang terjadi variable dan untuk mengukur kekuatan hubungan (Gravetter \& Forzano, 2012).

Populasi penelitian ini adalah seluruh karyawan di $\mathrm{MN}$ yang berjumlah 178 orang. Teknik sampling yang digunakan pada penelitian ini adalah Purposive sampling. Purposive sampling adalah teknik sampling yang digunakan oleh peneliti jika peneliti mempunyai pertimbangan-pertimbangan tertentu di dalam pengambilan sampelnya (Arikunto, 2013). Karakteristik sampel yang digunakan adalah karyawan MN tetap dan telah bekerja minimal selama enam bulan. Sampel dalam penelitian ini adalah karyawan MN dari tingkat staff, supervisor dan manager sebanyak 152 orang.

Teknik yang digunakan untuk mengumpulkan data adalah dengan menggunakan instrumen psychological capital yang telah diadaptasi peneliti dari Luthans, F., Avolio, B., Avey, J., \& Norman, S (2006) dan stres kerja yang dibuat oleh peneliti dengan menggunakan teori stres kerja yang dikemukakan oleh Karasek dan Johnson (dalam Revalicha dan Samian, 2013).

\section{HASIL DAN PEMBAHASAN}

\section{Hasil}

Tabel 1. Persentase Jenis Kelamin Subjek Penelitian

\begin{tabular}{cccc}
\hline No & $\begin{array}{c}\text { Jenis } \\
\text { Kelamin }\end{array}$ & Jumlah & Persentase \\
\hline 1. & Laki-laki & 53 & $45,30 \%$ \\
2. & Perempuan & 64 & $54,70 \%$ \\
\hline & Total & 117 & $100 \%$ \\
\hline
\end{tabular}


Versi Online: http://journal.ubm.ac.id/index.php/psibernetika DOI: 10.30813/psibernetika.v13i1.2313

Hasil Penelitian

Tabel 2. Persentase Subjek berdasarkan Usia

\begin{tabular}{cccc}
\hline No & Usia & Jumlah & Persentase \\
\hline 1. & $\begin{array}{c}21-25 \\
\text { tahun }\end{array}$ & 37 & $31,61 \%$ \\
2. & $\begin{array}{c}26-30 \\
\text { tahun }\end{array}$ & 45 & $38,50 \%$ \\
3. & $\begin{array}{l}31-35 \\
\text { tahun }\end{array}$ & 21 & $17,94 \%$ \\
4. & $\begin{array}{l}36-40 \\
\text { tahun }\end{array}$ & 8 & $6,83 \%$ \\
5. & $\begin{array}{l}41-45 \\
\text { tahun }\end{array}$ & 6 & $5,12 \%$ \\
\hline & Total & 117 & $100 \%$ \\
\hline
\end{tabular}

Tabel 3. Persentase Jabatan Subjek Penelitian

\begin{tabular}{ccc}
\hline Jabatan & Jumlah & Persentase \\
\hline Staff & 101 & $86,3 \%$ \\
Supervisor & 13 & $11,1 \%$ \\
Manager & 3 & $2,6 \%$ \\
\hline Total & 117 & $100 \%$ \\
\hline
\end{tabular}

Tabel 4. Persentase Divisi Subjek Penelitian

\begin{tabular}{cccc}
\hline No & Divisi & Jumlah & Persentase \\
\hline 1. & Accounting & 3 & $2,56 \%$ \\
2. & Content & 56 & $47,86 \%$ \\
3 & Finance & 4 & $3,42 \%$ \\
4 & GA & 3 & $2,56 \%$ \\
5 & HRD & 2 & $1,70 \%$ \\
6 & Marketing & 11 & $9,40 \%$ \\
7 & Network & 11 & $9,40 \%$ \\
8 & Sales & 23 & $19,70 \%$ \\
9 & Teknik & 2 & $1,70 \%$ \\
10 & Legal & 2 & $1,70 \%$ \\
\hline & Total & 117 & $100 \%$ \\
\hline
\end{tabular}

Tabel 5. Persentase Lama Bekerja Subjek Penelitian

\begin{tabular}{cccc}
\hline No & $\begin{array}{c}\text { Lama } \\
\text { Bekerja }\end{array}$ & Jumlah & Persentase \\
\hline 1 & $<1-5$ tahun & 91 & $77,78 \%$ \\
2 & $6-10$ tahun & 14 & $11,97 \%$ \\
3 & $11-15$ tahun & 8 & $6,83 \%$ \\
4 & $16-20$ tahun & 4 & $3,42 \%$ \\
\hline
\end{tabular}

Jurnal Psibernetika

Vol.13 (No.1) : 9 -19. Th. 2020

$p-I S S N: 1979-3707$

e-ISSN: 2581-0871

\begin{tabular}{ccc}
\hline Total & 117 & $100 \%$ \\
\hline
\end{tabular}

Tabel 6. Norma dan Persentase Psychological Capital Subjek Penelitian

\begin{tabular}{ccccc}
\hline No & $\begin{array}{c}\text { Klasifi } \\
\text { kasi } \\
\text { psycho } \\
\text { logical } \\
\text { capital }\end{array}$ & $\begin{array}{c}\text { Batas } \\
\text { Skor } \\
\text { psycholo } \\
\text { gical } \\
\text { capital }\end{array}$ & $\begin{array}{c}\text { Jumlah } \\
\text { Subjek }\end{array}$ & $\begin{array}{c}\text { Persen } \\
\text { tase }\end{array}$ \\
\hline 1. & $\begin{array}{c}\text { Sangat } \\
\text { Renda } \\
\text { h }\end{array}$ & $<44$ & 30 & $25,64 \%$ \\
& & & \\
2. & $\begin{array}{c}\text { Renda } \\
\text { h }\end{array}$ & $44-50$ & 33 & $28,21 \%$ \\
3. & $\begin{array}{c}\text { Tinggi } \\
\text { 4. }\end{array}$ & $51-57$ & 29 & $24,78 \%$ \\
& Sangat \\
Tinggi & $>57$ & 25 & $21,37 \%$ \\
\hline & & Total & 117 & $100 \%$ \\
\hline
\end{tabular}

Peneliti membuat kategori
gambaran psychological capital berdasarkan nilai persentil yang didapatkan. Kategori tersebut terbagi kedalam empat kategori, yaitu kategori sangat rendah untuk skor kurang dari 44, kategori rendah untuk skor 44-50, kategori tinggi untuk skor 5156 , dan kategori sangat tinggi untuk skor lebih dari 56. Jumlah Subjek terbanyak ada pada kategori psychological capital rendah.

Tabel 7. Norma dan Persentase Stres Kerja Karyawan MN

\begin{tabular}{ccccc}
\hline No & $\begin{array}{c}\text { Klasifikasi } \\
\text { Stres } \\
\text { Kerja }\end{array}$ & $\begin{array}{c}\text { Batas } \\
\text { Skor } \\
\text { Stres } \\
\text { Kerja }\end{array}$ & $\begin{array}{c}\text { Jumlah } \\
\text { Subjek }\end{array}$ & \% \\
\hline 1. & $\begin{array}{c}\text { Sangat } \\
\text { Rendah }\end{array}$ & $<45$ & 26 & $22,22 \%$ \\
2. & Rendah & $45-$ & 27 & $23,07 \%$ \\
& & 49 & & \\
3. & Tinggi & $50-$ & 33 & $28,21 \%$ \\
& & 57 & & \\
4. & Sangat & $>57$ & 31 & $26,50 \%$ \\
& Tinggi & & & \\
\hline & & Total & 117 & $100 \%$ \\
\hline
\end{tabular}

Peneliti membuat kategori stres kerja berdasarkan nilai persentil yang didapatkan. 
Versi Online: http://journal.ubm.ac.id/index.php/psibernetika DOI: 10.30813/psibernetika.v13i1.2313

Hasil Penelitian

Kategori tersebut terbagi kedalam empat kategori, yaitu kategori rendah untuk skor stres kerja kurang dari 45, kategori cenderung rendah untuk skor stres kerja 4549, kategori cenderung tinggi untuk skor stres kerja 50-57, dan kategori tinggi untuk skor lebih dari 57.

\section{Hubungan antara Psychological Capital dengan Stres Kerja pada karyawan PT.MN}

Peneliti melakukan pengujian ada atau tidaknya hubungan antara psychological capital dengan stres kerja dengan menggunakan uji korelasi Pearson pada program SPSS 17. Uji korelasi Pearson dilakukan karena data yang diperoleh dalam penelitian ini terdistribusi secara normal. Hasil analisis data korelasi Pearson menunjukkan nilai $\mathrm{p}=0,000(\mathrm{p}<$ $0,05)$. Hal ini menunjukkan bahwa keputusan $\mathrm{Ha}$ diterima yaitu terdapat hubungan antara psychological capital dengan stres kerja pada karyawan PT.MN. Nilai Pearson Correlation (r) sebesar 0,731 . Hal ini menunjukkan hubungan yang kuat antara psychological capital dengan stres kerja. Arti negatif adalah hubungan antara variabel psychological capital dengan stres kerja tidak searah, maksud dari tidak searah adalah semakin tinggi psychological capital maka semakin rendah stres kerja yang dirasakan. Begitu pula sebaliknya, semakin rendah, psychological capital, maka semakin tinggi stres kerja yang dirasakan.
Jurnal Psibernetika

Vol.13 (No.1) : 9 -19. Th. 2020

p-ISSN: 1979-3707

e-ISSN: 2581-0871

Tabel 8. Tabel Uji Korelasi Dimensi

Psychological Capital dengan stres kerja

\section{Hasil Korelasi}

\begin{tabular}{cccc}
\hline $\begin{array}{c}\text { Dimensi } \\
\text { Psycap } \\
\text { dengan }\end{array}$ & $\begin{array}{c}\text { Nilai } \\
\mathbf{p}\end{array}$ & Nilai $\mathbf{r}$ & $\begin{array}{c}\text { Kekuatan } \\
\text { Korelasi }\end{array}$ \\
$\begin{array}{c}\text { Stres } \\
\text { Kerja }\end{array}$ & & & \\
\hline $\begin{array}{c}\text { Self } \\
\text { Efficacy }\end{array}$ & 0,000 & $-0,655$ & Kuat \\
Hope & 0,000 & $-0,673$ & Kuat \\
Resiliency & 0,000 & $-0,556$ & Cukup \\
Optimism & 0,000 & $-0,716$ & Kuat \\
\hline
\end{tabular}

\section{Pembahasan}

Berdasarkan hasil penelitian, diperoleh gambaran psychological capital yang rendah dimiliki oleh karyawan MN. Hal tersebut ditunjukkan dengan jumlah kategori terbanyak adalah sangat rendah $(25,64 \%)$ dan rendah $(28,21 \%)$ sehingga dapat disimpulkan total persentase kategori psychological capital cenderung rendah sebesar 53,85\%. Gambaran psychological capital dapat dilihat dari empat dimensi yaitu self efficacy, hope, resiliency dan optimism yang nantinya akan dibahas per dimensi oleh peneliti.

Sementara itu, mengenai gambaran stres kerja, karyawan MN memiliki gambaran stres kerja yang tinggi dengan kategori tinggi $(28,21 \%)$ dan sangat tinggi $(23,07 \%)$ sehingga dapat disimpulkan total persentase kategori stres kerja cenderung tinggi sebesar $54,71 \%$. Gambaran stres kerja dapat dilihat dari tiga dimensi yaitu, demands, control dan social support.

Pada dimensi demands, terlihat gambaran tuntutan kerja yang tinggi $(37,62 \%)$ dan sangat tinggi $(17,09 \%)$ sehingga dapat disimpulkan total persentase kategori demands cenderung tinggi sebesar $54,71 \%$. Demands adalah persepsi seseorang mengenai seberapa keras ia bekerja, di mana subdimensi yang digunakan adalah beban kerja (workload), tekanan dalam waktu, dan personal conflict (Karasek \& Theorell dalam Revalicha dan Samian, 2013). Tuntutan kerja yang diberikan kepada karyawan MN meliputi 
Versi Online: http://journal.ubm.ac.id/index.php/psibernetika DOI: 10.30813/psibernetika.v13i1.2313

Hasil Penelitian

deadline untuk mengerjakan tugas singkat, target kerja yang tinggi dan terkadang masih bekerja saat hari libur sehingga karyawan merasa terbeban dalam mengerjakan tugas-tugasnya.

Pada dimensi control terlihat gambaran kontrol yang rendah $(40,17 \%)$ dan sangat rendah $(10,26 \%)$ sehingga dapat disimpulkan total persentase kategori control cenderung rendah sebesar 50,43\%. Kontrol kerja yang rendah dapat dilihat dari karyawan yang sering mengalami kesulitan dalam mengerjakan tugas, kesulitan mempelajari hal-hal baru, tidak diberikan kesempatan untuk menjalankan ide-ide baru yang dimiliki dan sering mengalami kebingungan dalam menyelesaikan masalah pekerjaan.

Berbeda halnya dengan dimensi social support (dukungan sosial). Pada dukungan sosial terlihat gambaran dukungan yang tinggi $(34,19 \%)$ dan sangat tinggi $(23,08 \%)$ sehingga dapat disimpulkan total persentase kategori social supports cenderung tinggi sebesar 57,27\%. Dukungan sosial yang tinggi dapat dilihat dari hubungan yang baik dengan rekan kerja dan atasan seperti tidak terlibat konflik, memiliki waktu bersama diluar jam kerja (jalan-jalan, gathering, merayakan ulang tahun, dsb) dan adanya kerja sama yang baik dengan rekan kerja maupun atasan.

Menurut Karasek (dalam Revalicha dan Samian, 2013), ketika demands (tuntutan kerja) yang diberikan tinggi namun kontrol yang dimiliki rendah (high job strain), maka akan membuat stres kerja pada karyawan. Hal ini sesuai dengan keadaan yang terjadi pada karyawan MN, yaitu mereka mengalami stres kerja karena adanya tuntutan kerja yang diberikan tinggi namun kontrol yang dimiliki rendah. Namun dengan adanya dukungan sosial yang tinggi dapat mengurangi stres kerja yang dirasakan (Karasek dalam Revalicha dan Samian, 2013).

Hasil uji korelasi psychological capital dengan stres kerja menunjukkan adanya hubungan negatif signifikan antara psychological capital dengan stres kerja.
Jurnal Psibernetika

Vol.13 (No.1) : 9 -19. Th. 2020

p-ISSN: 1979-3707

e-ISSN: 2581-0871

Hal tersebut dibuktikan dengan nilai korelasi sebesar -0,731. Angka tersebut menunjukkan hubungan yang kuat antara psychological capital dengan stres kerja, sehingga dapat dikatakan bahwa hipotesa penelitian diterima. Arti negatif menunjukkan hubungan yang tidak searah antara psychological capital dengan stres kerja yaitu semakin tinggi psychological capital maka semakin rendah stres kerja yang dirasakan. Begitu pula sebaliknya, semakin rendah psychological capital, maka semakin tinggi stres kerja yang dirasakan.

Mengenai gambaran psychological capital pada dimensi self efficacy, terlihat gambaran self efficacy pada karyawan MN adalah rendah. Hal ini terlihat pada jumlah kategori terbanyak yaitu rendah $(30,77 \%)$ dan sangat rendah $(20,51 \%)$ sehingga dapat disimpulkan total persentase kategori self efficacy cenderung rendah sebesar 51,28\%. Menurut Luthans dan Youssef (2007), self efficacy merupakan keyakinan untuk melakukan dan terlibat dalam usaha yang diperlukan agar berhasil dalam tugas yang menantang. Dapat disimpulkan bahwa sebagian besar karyawan MN memiliki keyakinan dan usaha yang rendah atau kurang memiliki keyakinan dan usaha untuk mengerjakan tugas-tugas yang diberikan. Self efficacy yang rendah memiliki ciri-ciri kurangnya percaya diri, motivasi diri yang rendah dan tidak memiliki target atau tujuan yang tinggi. Karyawan yang memiliki ciri-ciri tersebut jika dihadapkan dengan tuntutan kerja yang tinggi maka akan menghasilkan stres kerja karena adanya ketidakseimbangan antara tuntutan kerja yang diberikan dengan self efficacy yang dimiliki. Hal ini dibuktikan dengan hasil penelitian yang menunjukkan bahwa self efficacy memiliki hubungan yang kuat dengan stres kerja $(r=-0,655)$.

Mengenai dimensi hope, terlihat gambaran hope yang dimiliki oleh karyawan MN juga rendah. Hal ini terlihat dari jumlah kategori terbanyak yaitu pada kategori rendah $(35,05 \%)$ dan sangat rendah $(18,81 \%)$ sehingga dapat disimpulkan total persentase kategori hope cenderung rendah 
Versi Online: http://journal.ubm.ac.id/index.php/psibernetika DOI: 10.30813/psibernetika.v13i1.2313 Hasil Penelitian

sebesar 53,86\%. Menurut Snyder (dalam Dewi, 2015) hope adalah proses kognisi atau berpikir dimana individu mampu menyusun tujuan dan pengharapan yang menantang namun realistis dan kemudian bertindak untuk mencapainya dengan kemampuan diri, energi dan kontrol persepsi internal. Hope memiliki komponen agency/will power dan pathways. Agency adalah kemampuan, energi, dan persepsi kontrol internal yang dimiliki untuk mencapai tujuan-tujuan yang telah ditetapkan, sedangkan pathways adalah ketika seseorang mampu menciptakan jalurjalur alternatif untuk mencapai tujuan yang mereka inginkan ketika jalur asalnya tertutup atau mendapat halangan.

Pada karyawan MN yang memiliki hope rendah, artinya mereka tidak mampu mengembangkan kemampuan, energi dan persepsi kontrol internal dan menciptakan jalur alternatif untuk mencapai tujuan. Hal ini ditunjukkan seperti tidak bersemangat dalam mencapai tujuan pekerjaan yang diinginkan, kesulitan menciptakan kreasi dan inovasi baru dalam bekerja dan menyelesaikan masalah serta tidak mampu dalam mencapai tujuan pekerjaan yang telah ditetapkan oleh diri sendiri. Jika dihubungkan dengan stres kerja, karyawan MN dengan hope yang rendah memiliki kontrol kerja yang rendah dan jika dihadapkan dengan tuntutan kerja yang tinggi maka akan menghasilkan stres kerja. Hal ini disebabkan adanya ketidakseimbangan antara tuntutan kerja, kontrol kerja dengan hope yang dimiliki. Hal ini dibuktikan dengan hasil penelitian yang menunjukkan bahwa hope memiliki hubungan negatif yang kuat dengan stres $\operatorname{kerja}(\mathrm{r}=-0,673)$.

Pada dimensi resiliency terlihat karyawan MN juga memiliki gambaran resiliency yang rendah. Hal ini terlihat dari jumlah kategori terbanyak yaitu sangat rendah $(39,31 \%)$ dan rendah $(18,80)$ sehingga dapat disimpulkan total persentase kategori resiliency cenderung rendah sebesar 58,11\%. Menurut Luthans dan Youssef (2007), resiliency adalah tidak hanya memiliki kemampuan untuk kembali
Jurnal Psibernetika

Vol.13 (No.1) : 9 -19. Th. 2020

p-ISSN: 1979-3707

e-ISSN: 2581-0871

dari situasi kegagalan namun juga terlibat dalam kegiatan-kegiatan yang positif dan menantang, dan kemauan untuk berusaha melebihi normal atau melebihi keseimbangan. Dapat disimpulkan bahwa karyawan MN yang memiliki resiliency rendah ketika menghadapi situasi kegagalan atau masa-masa sulit, mereka mengalami kesulitan untuk bangkit kembali dari situasi tersebut, tidak dapat diberikan tugas-tugas yang menantang, dan tidak memiliki kemauan untuk berusaha melebihi dari target yang telah ditetapkan. Hal inilah yang membuat karyawan MN mengalami stres kerja ketika diberikan tuntutan kerja yang tinggi. Hal ini disebabkan adanya ketidakseimbangan antara tuntutan kerja, kontrol kerja dengan resiliency yang dimiliki. Hal ini dibuktikan dengan hasil penelitian yang menunjukkan bahwa resiliency memiliki hubungan negatif yang cukup dengan stres kerja $(\mathrm{r}=-0,556)$.

Berbeda dengan dimensi optimism, pada dimensi ini karyawan MN memiliki gambaran optimism yang tinggi. Hal ini dapat terlihat dari kategori terbanyak adalah tinggi $(47 \%)$ dan sangat tinggi $(17,95 \%)$ sehingga dapat disimpulkan total persentase kategori optimism cenderung tinggi sebesar $63,25 \%$. Menurut Luthans (2007), optimism adalah atribusi positif mengenai kesuksesan di masa kini dan masa depan. Individu yang memiliki optimism tinggi, maka mereka memandang bahwa penyebab dari peristiwa-peristiwa yang menyenangkan dalam pekerjaan mereka berada dalam kekuasaan dan kontrol diri mereka dan berpikir bahwa penyebab peristiwaperistiwa tersebut akan terus ada dimasa depan dan akan membantu mereka menangani peristiwa lain dalam hidupnya. Pada karyawan MN, optimism yang tinggi terlihat dari karyawan yang selalu melihat sisi baik dalam pekerjaan, merasa yakin mengenai hal-hal yang terjadi pada dirinya di masa depan, dan memiliki prinsip bahwa pasti terdapat hasil yang memuaskan atas usaha yang dilakukan. Karyawan yang memiliki optimism yang tinggi dapat mengurangi stres kerja yang dirasakan. Hal ini dibuktikan dengan hasil penelitian yang 
Versi Online: http://journal.ubm.ac.id/index.php/psibernetika DOI: 10.30813/psibernetika.v13i1.2313

Hasil Penelitian

menunjukkan bahwa optimism memiliki hubungan negatif yang kuat dengan stres $\operatorname{kerja}(\mathrm{r}=-0,716)$.

Mengenai gambaran subjek berdasarkan jenis kelamin, usia, divisi, jabatan dan lama bekerja tidak ditemukan adanya hubungan dengan psychological capital maupun dengan stres kerja yang dimiliki. Hal ini dibuktikan dengan hasil perhitungan psychological capital dengan jenis kelamin $(\mathrm{p}=0,783)$, psychological capital dengan usia $(\mathrm{p}=0,330)$, psychological capital dengan jabatan $(\mathrm{p}=$ 0,079), psychological capital dengan jabatan $(\mathrm{p}=0,149)$, psychological capital dengan divisi $(\mathrm{p}=0,149)$ dan psychological capital dengan lama bekerja $(\mathrm{p}=0,392)$. Sementara itu hasil perhitungan stres kerja dengan jenis kelamin $(\mathrm{p}=0,497)$, stres kerja dengan usia $(p=0,057)$, stres kerja dengan jabatan $(\mathrm{p}=0,138)$, stres kerja dengan divisi $(\mathrm{p}=0,651)$, dan stres kerja dengan lama bekerja $(p=0,491)$. Semua nilai $\mathrm{p}$ yang diperoleh menunjukkan nilai $\mathrm{p}$ $>0,05$ yang menunjukkan tidak terdapat hubungan antara jenis kelamin, usia, divisi, jabatan dan lama bekerja dengan psychological capital maupun dengan stres kerja yang dimiliki.

\section{SIMPULAN}

Kesimpulan yang diperoleh dari penelitian ini adalah karyawan MN memiliki gambaran psychological capital yang cenderung rendah. Mengenai stres kerja, karyawan MN memiliki gambaran stres kerja yang cenderung tinggi. Penelitian ini menunjukkan adanya hubungan antara psychological capital dengan stres kerja pada karyawan MN dengan korelasi sebesar -0,731. Pada dimensi psychological capital menunjukkan adanya korelasi dengan stres kerja yang kuat seperti self efficacy dengan stres kerja $(\mathrm{r}=-0,655)$, hope dengan stres kerja $(\mathrm{r}=-0,673)$, optimism dengan stres kerja $(\mathrm{r}=-0,716)$, sedangkan korelasi yang cukup ditunjukkan pada dimensi resiliency dengan stres kerja $(\mathrm{r}=-0,556)$.
Jurnal Psibernetika

Vol.13 (No.1) : 9 -19. Th. 2020

p-ISSN: 1979-3707

e-ISSN: 2581-0871

\section{Saran Teoritis}

Saran untuk penelitian selanjutnya adalah diharapakan peneliti dapat meninjau kembali instrumen stres kerja karena cukup banyak item yang dibuang dalam penelitian ini. Selain itu, peneliti selanjutnya juga dapat mengembangkan penelitian mengenai human capital seperti intelectual capital, emotional capital, dan social capital dengan stres kerja.

\section{Saran Praktis}

Saran untuk pihak MN sebaiknya meningkatkan psychological capital pada karyawan yang mencakup pengembangan self efficacy, hope, resiliency dan optimism dan mengatasi stres kerja yang mereka rasakan dengan cara memberikan pelatihanpelatihan kepada karyawan. Saran untuk karyawan MN adalah karyawan dapat mengembangkan psychological capital dengan mengikuti pelatihan dan mengikuti fasilitas konseling yang disediakan oleh $\mathrm{MN}$, serta melakukan kegiatan-kegiatan yang dapat mengurangi stres misalnya mendengarkan musik, makan makanan ringan, bersenda gurau sejenak, dsb untuk dapat mengurangi stres kerja yang dirasakan.

\section{DAFTAR PUSTAKA}

Aamodt, M. G. (2007). Industrial / Organizational psychology. USA: Wadsworth Cengange Learning Anoraga, P. (2009). Psikologi kerja. Jakarta: Rineka Cipta

Arikunto, S. (2013). Manajemen penelitian. Jakarta: Rineka Cipta

Candra, Asep. (2012). 30 persen pekerja kantor alami stres. Diunduh 13 Oktober 2015 dari http://health.kompas.com/read/pers en.pekerja.kantor.alami.stres

Cohen, R.J \& Swerdlik, M.E. (2010). Psychological testing and assessment. New York: McGrawHill

Crocker, L \& Algina J. T. (2006). Introduction to classical and 
Versi Online: http://journal.ubm.ac.id/index.php/psibernetika DOI: 10.30813/psibernetika.v13i1.2313

Hasil Penelitian

modern test theory. Florida: Harcourt Brace

Dewi, D. N., (2015). Kajian peran psychological capital dalam membentuk safety performance. Embracing a New Way of life: Promoting Positive Psychology for Better a Mental Health (Proceeding). Surabaya: Universitas Katolik Widya Mandala

Gulo. (2010). Metode penelitian. Jakarta: Grasindo

Gravetter, F.J. \& Forzano, L.A.B. (2012). Research methods for the behavior sciences. Kanada: Wadsworth Cengange Learning

Harianto, F., Wiguna, P. A \& Rakhmad, D. (2008). Pengaruh stres kerja, motivasi kerja, dan gaya kepemimpinan terhadap kinerja tenaga kerja pada proyek Mall Yani Golf Di Surabaya. Jumal IPTEK, $l$ $l(3)$, h.138-146.

Hedissa, A. T., Sukirman, I \& Supandi, A. (2012). Hubungan psychological capital dengan kepuasan kerja pada anggota polri yang sedang mengikuti pendidikan di Perguruan Tinggi Ilmu Kepolisian (PTIK). Jurnal Psikologi Pitutur, 1(1), h.18

Iresa, Utami, \& Prasetya. (2015). Pengaruh konflik kerja dan stres kerja terhadap komitmen organisasional dan kinerja karyawan (Studi pada Karyawan PT. Telekomunikasi Indonesia, Tbk Witel Malang). Jurnal Administrasi Bisnis, 23(1), h. $1-10$

Luthans, F. (2008). Organizational behavior. USA: McGraw-Hill

Luthans, F., Avey, J. B \& Jensen, S. M. (2009). Psychological capital: A positive resource for combating employee stress and turnover. Human Resource Management, 48(5), h.677-693.

Luthans, F., Youssef C.M. \& Avolio, B.J. (2007). Psychological capital: Developing the human competitive
Jurnal Psibernetika Vol.13 (No.1) : 9 -19. Th. 2020 p-ISSN: 1979-3707 e-ISSN: 2581-0871

edge. New York: Oxford University Press

Munandar, A.S. (2006). Psikologi industri dan organisasi. Jakarta: Penerbit UI

MNC. (2015). Profil MNC. Diunduh 19 Oktober dari http://mnc.co.id/profil mnc

MN. (2015). Profil MN. Diunduh 19 Oktober dari http://www.MNetworks.com/profil $\mathrm{MN}$

Nazir, M. (2009). Metode penelitian. Jakarta: Ghalia Indonesia

Nisfianoor. (2009). Pendekatan statistika modern. Jakarta: Salemba Humanika

Paramita. (2012). Metode penelitian kuantitatif. Bandung: Alfabeta

Peng, Jiang, Shang. (2013). The impact of psychological capital on job burnout of Chinese nurses: The mediator role of organizational commitment. Plos One, 8(12), h.17.

Rea, G. S \& Hadi, C. (2012). Kebosanan kerja pada karyawan radio Sonora Surabaya. Jurnal Psikologi Industri dan Organisasi, 1(2), h.131-139.

Revalicha, N,S \& Samian. (2013). Perbedaan stres kerja ditinjau dari shift kerja pada perawat di RSUD Dr. Soetomo Surabaya. Jurnal Psikologi Industri dan Organisasi, 2(1), h.16-24.

Riggio, R.E. (2013). Industrial organizational psychology. USA: Pearson

Robbins, S. P. (2006). Perilaku organisasi. Jakarta: Indeks

Saleh, A. R. (2015). Analisis faktor konfimatorik skala modal psikologis. Embracing a New Way of Life: Promoting Positive Psychology for Better a Mental Health (Proceeding). Surabaya: Universitas Katolik Widya Mandala 
Seniati, L., Yulianto, A \& Setiadi., B. N. (2006). Psikologi eksperimen. Jakarta:Indeks

Setyowati, T., \& Nurhidayati, A. (2012). Pengaruh stres kerja terhadap kinerja dengan dukungan sosial sebagai variabel moderasi (studi kasus tim penggerak PKK Kabupaten Rembang). POTENSIO, 17(1), h.1-10.

Shahnawaz, M.G., \& Jafri. (2009). Psychological capital as predictors of organizational commitment and organizational citizenship behaviour. Journal of the Indian Academy of Applied Psychology, 35(1), h.78-84.

Siagian, S. P. (2010). Manajemen sumber daya manusia. Jakarta: Bumi Aksara.

Sinaga, M. T \& Sunardi, H. P. (2013). Analisis pengaruh stres kerja terhadap prestasi kerja karyawan pada PT. Bardie Puritama. Jurnal Ilmiah Manajemen Bisnis, 13(2), h. $77-90$

Sholichatun, Y. (2011). Stres dan Strategi Coping pada Anak Didik di Lembaga Pemasyarakatan Anak. PSIKOISLAMIKA, Jurnal Psikologi Islam, 8(1). 23-42

Siregar, Syofian. (2013). Metode Penelitian Kuantitatif. Jakarta: Kencana Prenada Media Group

Sugiyono. (2015). Statistika untuk Penelitian. Alfabeta: Bandung

Suryabarata. (2010). Metode Penelitian. Jakarta: Rajawali Pers

Tando, A. A. (2015). MEA 2015: AJANG KOMPETISI TENAGA KERJA. Diunduh 16 Maret 2016 dari http://suaramahasiswa.com/mea2015-ajang-kompetisi-kualitas tenaga- kerja

Yuliawan, E. (2012). Pengaruh Stres dan Konflik Terhadap Kinerja Pada PT. Pindad Bandung. Jurnal Wira Ekonomi Mikroskil, 22 (01), 11-20 